Proc. Indian Acad. Sci., Vol. 87 A (E \& P Sciences), No 3, March 1978, pp. 61-75, (C) printed in India.

\title{
Some studies of the growth of monsoon disturbances
}

\author{
R N KESHAVAMURTY*, G C ASNANI $\dagger$, P V PILLAI and S K DAS \\ Meteorological Office, Pune \\ *Present address: Physical Research Laboratory, Ahmedabad 380009 \\ †Department of Meteorology, University of Nairobi, Nairobi
}

MS received 8 October 1977; revised 13 January 1978

\begin{abstract}
The structure of the monsoon depression and the observed flow features prior to and at the time of monsoon depression formation (composite of 15 depressions) are examined. The composite monsoon depression (transient eddy) has a scale of $25^{\circ}$ longitude and extends up to $300 \mathrm{mb}$ and has the greatest intensity at $700 \mathrm{mb}$. It shows north-north-east to south-south-west tilt in the lower levels indicating that it may draw upon zonal kinetic energy for its growth. The disturbance has lower temperatures to its west and tilts westwards with height indicating that eddy available potential energy is not converted from zonal available potential energy by large scale advection. There appears to be a reduction of vertical shear at the time of formation of monsoon depressions and this possibly aids cumulus convection.

The profiles of potential vorticity indicate extremes (i) in the upper troposphere and (ii) at several midtropospheric levels in the region of the monsoon trough indicating the possibility of combined barotropic-baroclinic instability. Using multi-level quasi-geostrophic model and employing the eigen-value technique it is shown that the monsoon zonal current is not baroclinically unstable. A barotropic stability analysis is also done for monsoon zonal current in the lower and middle tropospheres. It yields very slowly growing unstable modes at lower tropospheric levels with wave lengths of $2500 \mathrm{~km}$ and $5000 \mathrm{~km}$.
\end{abstract}

Keywords. Monsoon disturbances; Eddy kinetic energy; static stability; Coriolis parameter; perturbation potential; perturbation stream function; barotropic-baroclinic instability.

List of symbols

$\begin{array}{lll}K_{E} & \ldots & \text { Eddy kinetic energy } \\ A_{E} & \ldots & \text { Eddy available potential energy } \\ {[x]} & \ldots & \text { Zonal mean of } x \\ x^{*} & = & x-[x] \\ U & \ldots & \text { Basic zonal wind } \\ \sigma & \ldots & \text { Static stability } \\ f & \ldots & \text { Coriolis parameter } \\ \beta & = & d f / d y \\ \boldsymbol{P} & \ldots & \text { Geopotential } \\ \boldsymbol{P}^{\prime} & \ldots & \text { Perturbation geopotential } \\ \boldsymbol{\phi}^{\prime} & \ldots & \text { Perturbation stream function } \\ \boldsymbol{C} & \ldots & \text { Phase speed of the wave perturbation } \\ U_{\boldsymbol{J}, k} & \ldots & \text { Mean zonal wind at latitude } j \text { and level } k .\end{array}$

\section{Introduction}

The lows and depressions which form over north Bay of Bengal and move westnorth-westwards across central and north India are the most important rain producing 
systems of the summer monsoon. Though about one third of these move into the Bay as remnants of northwest Pacific storms (Rao 1976), the main development of these systems occurs over north Bay. The formation of a monsoon depression is an important meteorological event during the monsoon season. There is need to understand the mechanism of formation of these depressions. There have been several earlier studies in this direction. Early studies emphasised air mass contrast as a source of energy. Koteswaram and George (1958) suggested the superposition of upper tropospheric easterly waves and associated differential vorticity advection as the initial mechanism and thermal advection as the later one favouring growth. Keshavamurty (1971) pointed out that baroclinic instability may not be the initial mechanism for formation of monsoon disturbances. He pointed out that these disturbances do not have the eastward tilt with height necessary for baroclinic growth initially and that the region of upward motion in the western sector is colder in the lower troposphere, whereas the momentum transport is of the right type for deriving energy from the basic flow. He also suggested that as the monsoon atmosphere is conditionally unstable and as cyclonic vorticity is always present in the lower levels, conditional instability of the second kind (CISK) may be an important process for the development of monsoon disturbances. Mak (1975) showed that $v$ component of basic motion may be important. Krishmamurti et al (1975) studied the structure of a monsoon depression and showed that it has a cold core in the lower troposhere and warm core in the upper troposphere. They suggested that some type of CISK mechanism may be important for the initial growth of monsoon disturbances. Shukla (1976) showed that cumulus heating and CISK mechanism are important for the growth of monsoon disturbances.

\section{Some features of the structure of monsoon depressions}

Figure 1 shows the tracks of monsoon depressions in July. The remarkable feature shown in this diagram is that the region of formation of monsoon depressions is limited to a small geographical region over the head Bay of Bengal. We have taken advantage of this climatological fact to get a picture of the mean depression in its formative stage by just taking the mean data of stations on the dates of formation of depressions (of 15 cases) one day before, 2 days before, etc. The depressions considered are those that formed on:

$\begin{array}{rr}26-7-1967 & 5-7-1973 \\ 31-7-1967 & 12-7-1973 \\ 3-8-1968 & 19-7-1973 \\ 11-8-1968 & 28-7-1976 \\ 28-7-1969 & 1-8-1976 \\ 8-8-1969 & 12-8-1976 \\ 17-8-1970 & 2-9-1976\end{array}$

Except for the last one all of them formed in July or August. Figure 2 shows the structure of the depression perturbation or eddy on the date of formation. What we have done is to remove the 5-day mean climatological wind, height, etc. from the corresponding day's data so that we get a picture of the perturbation that is the 


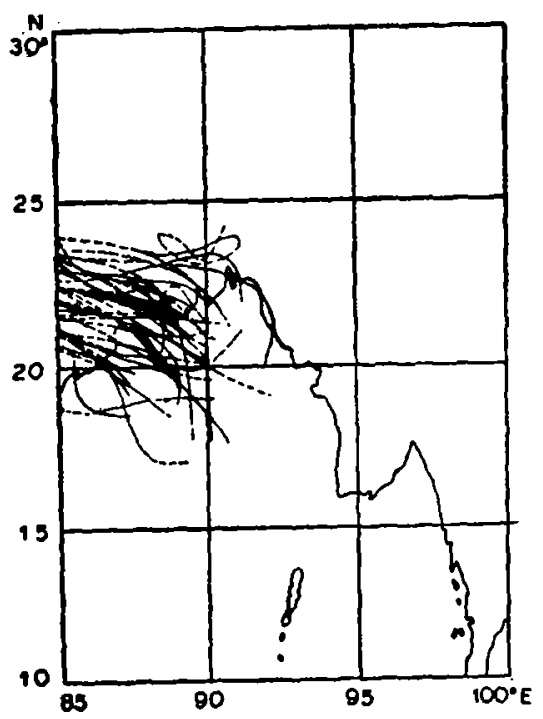

Figure 1. Initial tracks of monsoon depressions in July.

monsoon depression. It is seen that the cyclonic circulation extends up to $300 \mathrm{mb}$ and there is difluent flow aloft. At $850 \mathrm{mb}$ the scale of the disturbance in the $x$ direction is about $25^{\circ}$ longitude. This is taken as twice the distance from the depression centre over north Bay around $90^{\circ} \mathrm{E}$ and the perturbation ridge around $721^{\circ} \mathrm{E}$. The circulation is seen to be most intense at $700 \mathrm{mb}$.

If we examine the flow pattern at $850 \mathrm{mb}$ the axis of the trough extends from the centre of the depression over north Bay south-south-westwards to east of Madras. This tilt of the trough from north-north-east to south-south-west would be associated with northward transport of westerly momentum. As the maximum westerly winds are found over peninsular India this would indicate that the disturbance transports westerly momentum away from the region of maximum winds and thus derives energy from the kinetic energy of the basic current. In the equation:

$$
\frac{\partial K_{E}}{\partial t}=-\int\left[u^{*} v^{*}\right] \frac{\partial[u]}{\partial y} d m
$$

$\left[u^{*} v^{*}\right]$ will be positive and $(\partial[u] / \partial y)$ will be negative and thus $\partial K_{E} / \partial t$ will be positive. This would suggest that barotropic instability may be one of the mechanisms for the initial formation of monsoon depressions.

Figure 3 shows the thermal structure of the perturbation. It is seen that in the lower troposphere the western sector of the disturbance is colder than the eastern sector (relatively). In the upper troposphere also it is warm to the east and cold to the west. This would give a westward tilt of the perturbation with height as can be seen from the charts (figure 2). This is evident from the veering of the wind at Calcutta with height. For baroclinic growth we need an eastward tilt with height as discussed by Keshavamurty (1971).

There is another very interesting feature, the dynamical significance of which is not immediately evident. We see that especially in the upper troposphere the normal 


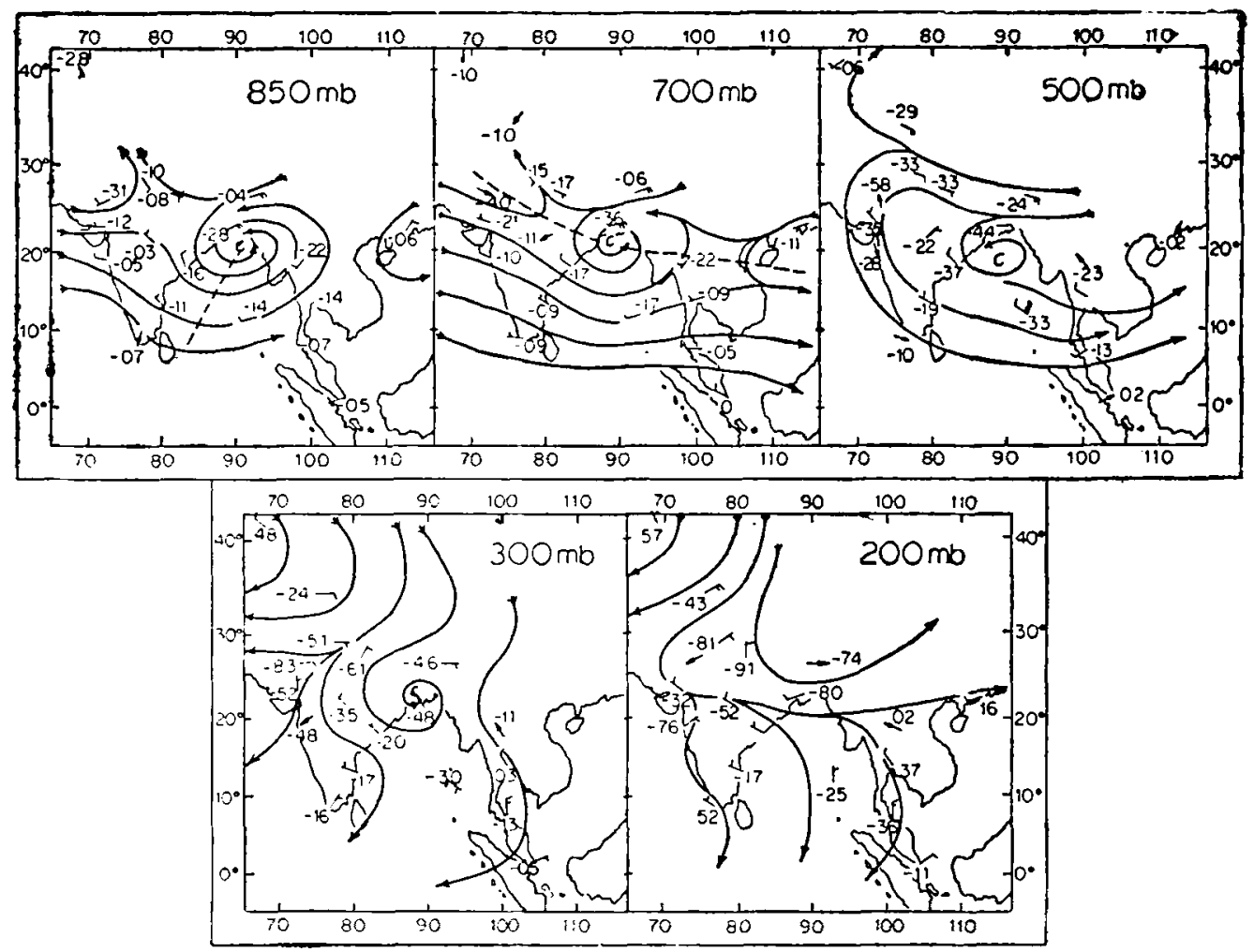

Figure 2. Composite depression eddy (transient disturbance), on the day of forma-
tion (15 cases).

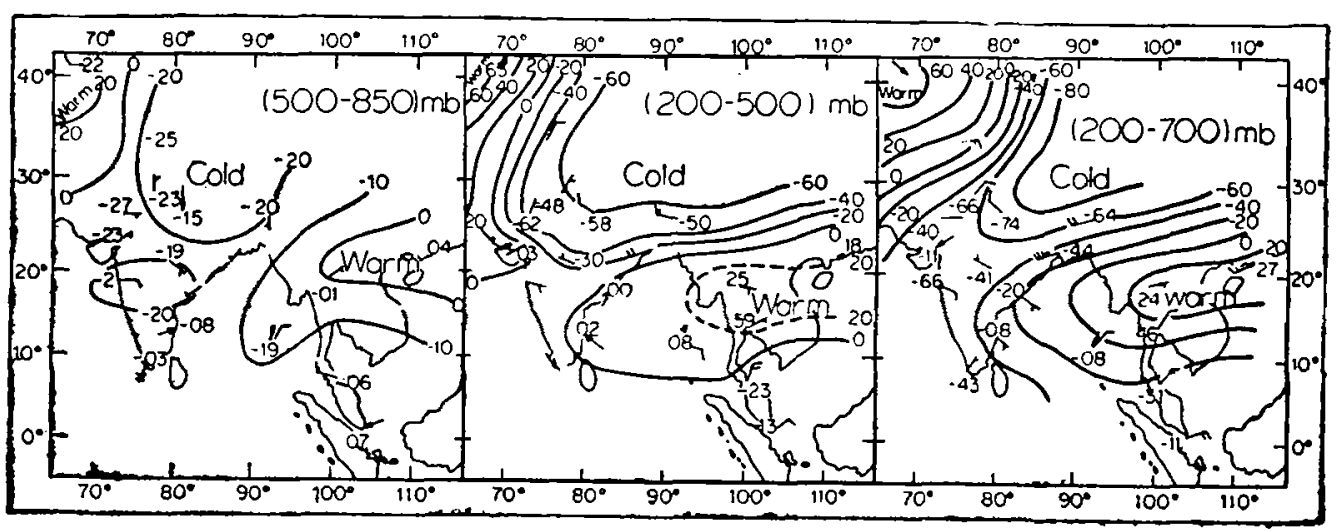

Figure 3. Composite thermal anomaly field, day of formation of the depression.

north-south temperature gradient is somewhat distorted at the time of the formation of monsoon depressions. There is a cold anomaly, over east Tibet and neighbourhood which is possibly due to radiational cooling or advection of cold air from the north. With the warm anomaly over Southeast Asia possibly due to the release of latent heat, there is a considerable reduction in the north-south temperature gradient 
and the normal easterly shear is considerably reduced. The reduction of the vertical shear possibly aids cumulus convection.

In the depression field, in the lower troposphere, to the west of the depression centre where the winds are northerly, the temperatures (or thickness) are lower than to the east of the depression centre where the winds are southerly. This would give a northward transport of sensible heat by the depression which is against the gradient of mean temperature. This indicates conversion from eddy available potential energy into zonal available potential energy, the eddy reinforcing the meridional temperature contrast. In the equation:

$$
\frac{\partial A_{E}}{\partial t}=-R^{2} \int \frac{1}{\sigma p^{2}}\left[v^{*} T^{*}\right] \frac{\partial[T]}{\partial y} d m
$$

$\left[v^{*}, T^{*}\right]$ is positive and $\partial[T] / \partial y$ is positive, so that $\partial A_{E} / \partial t$ is negative. The eddy available potential energy cannot grow by drawing on zonal available potential energy by large scale thermal advection. This would preclude the depression growing by the process of baroclinic instability, as baroclinic instability theory predicts that the growing disturbances transports sensible heat down the gradient of zonal mean temperature. Thus the only source for the eddy available potential energy could be diabatic sources like the release of latent heat.

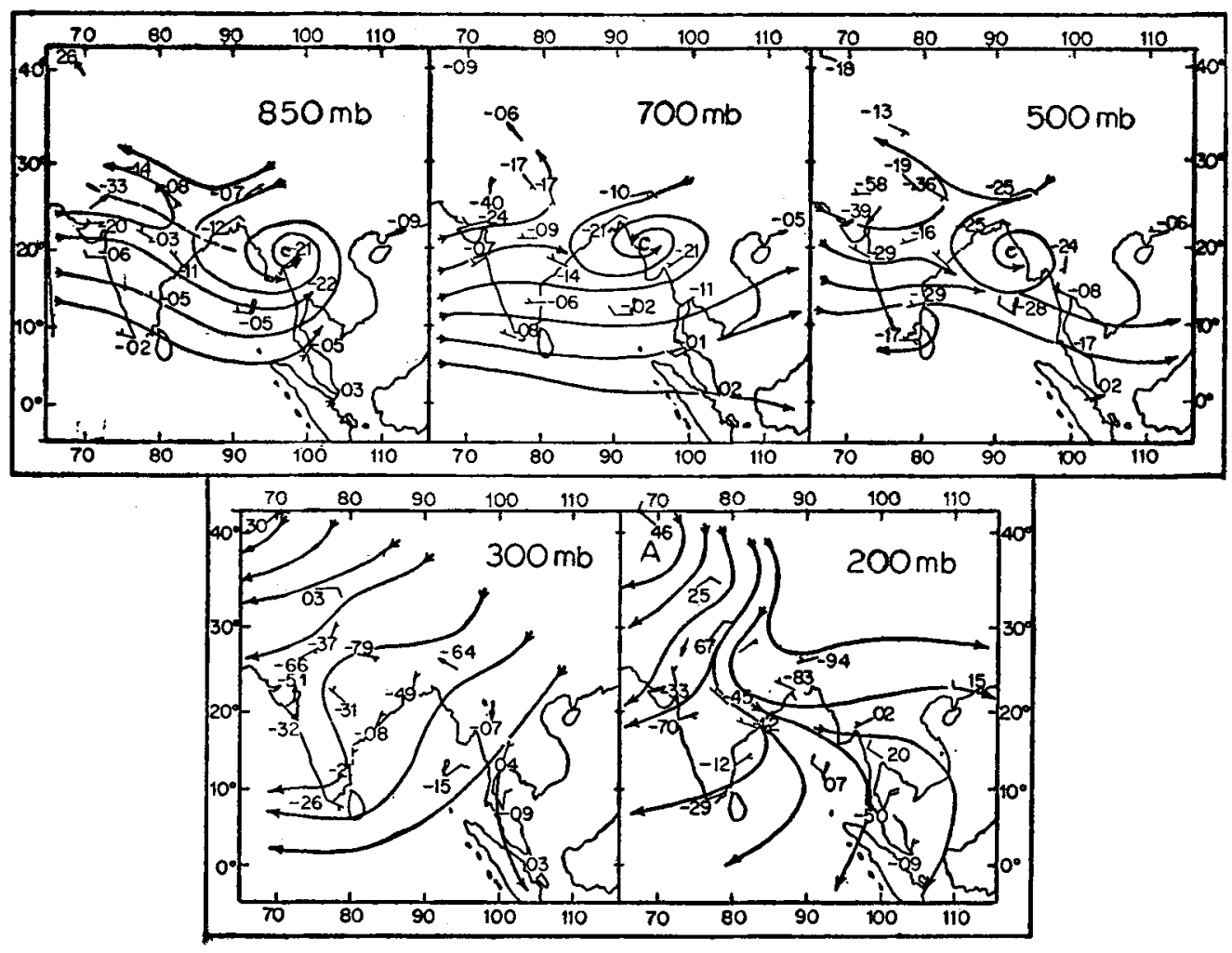

Figure 4. Composite transient disturbance, one day before depression formation. 
Figure 4 shows the transient disturbance (average) one day before the date of formation of the depression. It is seen that the disturbance is somewhat to the cast of the position on the depression day. This may be a special feature of the data sample and may not be common to all depressions. The circulation extends up to $500 \mathrm{mb}$ and tilts towards west. Marked difluent flow is seen at $200 \mathrm{mb}$. In the lower troposphere temperatures are lower in the western sector (figure 5). However, in the upper troposphere a warm region appears to overlie the disturbance indicating the importance of cumulus heating.

The mean thermal charts, however, indicate that, climatologically, in the region to the west of where depressions form, temperatures are higher than to the east both in the lower and upper tropospheres. There is an east-west temperature gradient with a northerly thermal wind. The effect of this on the growth of monsoon disturbances has been studied by Mak (1975).

An examination of the average thermal fields on the date of formation and the previous day [which contain the combined effect of the climatological mean (standing eddy or stationary disturbance) and the transient disturbance or the deviation from the time mean] reveals that the east-west thermal gradient is weakened by the transient perturbation, perhaps even changing the sign in the lower troposphere, as the shear wind indicates southerly component. Also the warm core of the depression in the layer $700-200 \mathrm{mb}$ on the day of formation is noteworthy. This indicates the importance of cumulus heating.

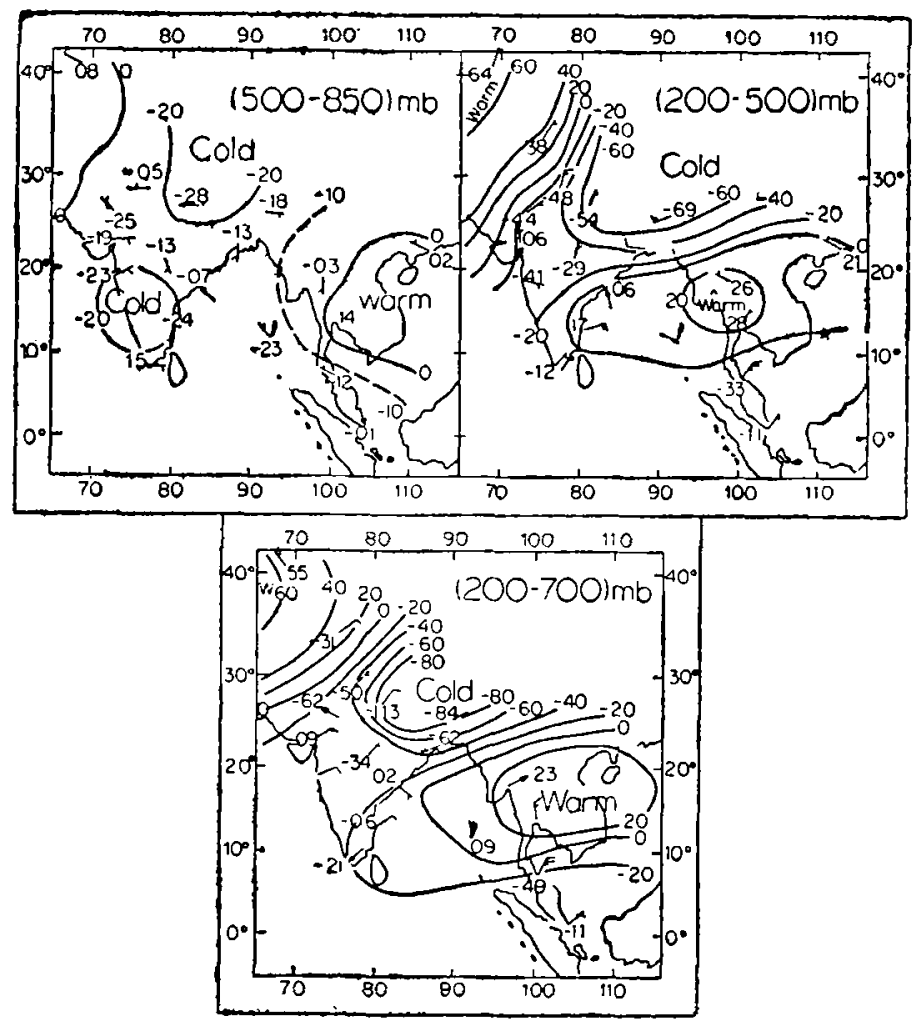

Figure 5. Composite thermal anomaly field, one day before depression formation. 


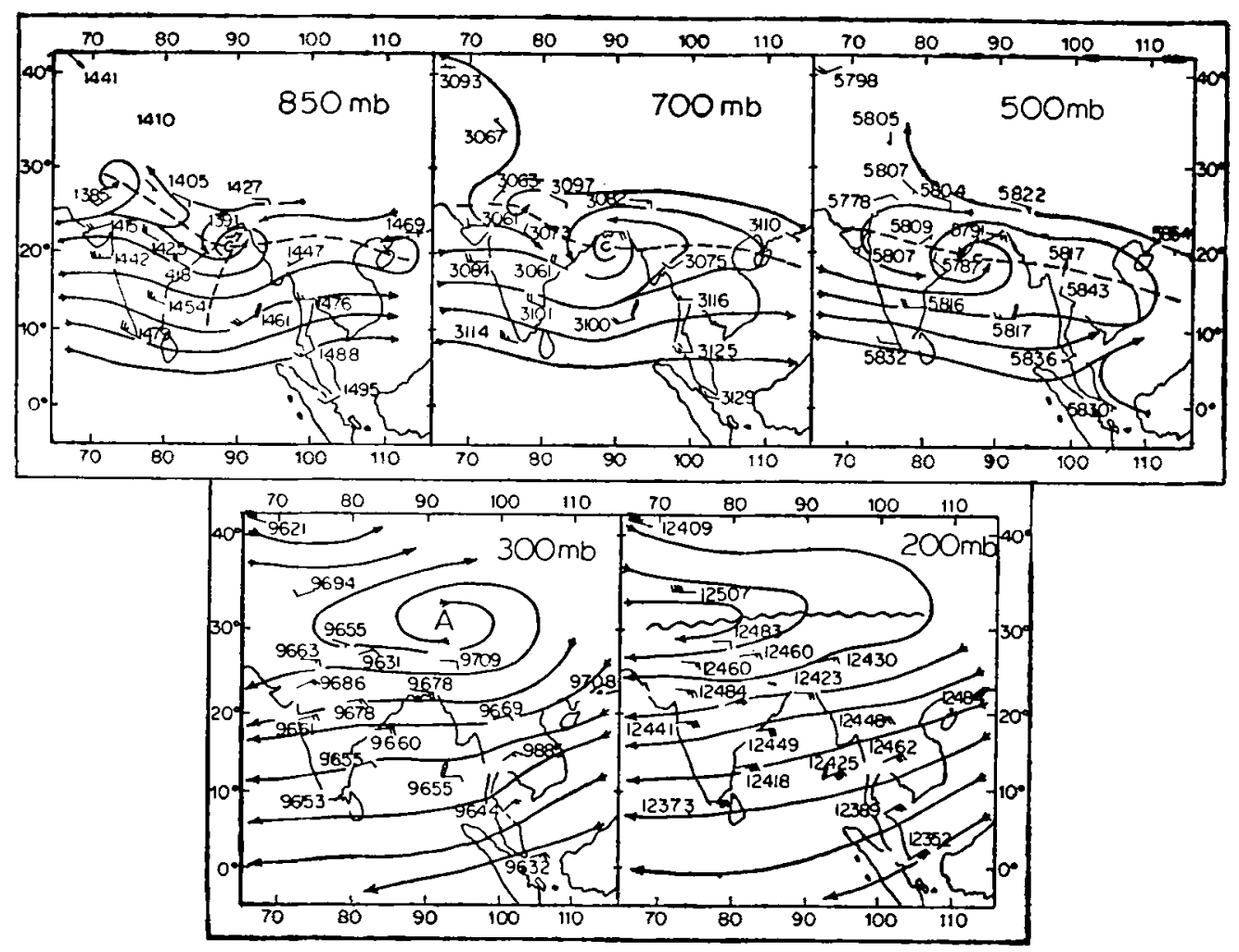

Figure 6. Composite wind field, on the day of formation of depression.

Figure 6 shows the composite wind field on the day of formation of the depression. This composite is the average of the actual data of the 15 cases on the date of formation and is the combined result of the transient eddy and the stationary monsoon flow. Even this composite indicates at $850 \mathrm{mb}$ the north-north-east-south-south-west tilt of the trough from the depression to east of Madras. The veering of Calcutta wind with height up to $400 \mathrm{mb}$ confirms the westward tilt of the transient disturbance. However, above this level there is backing of the wind indicating reversal of the eastwest temperature gradient possibly due to cumulus heating. Such clouding would be more abundant in the western sector and would warm the upper troposphere.

As the monsoon atmosphere is conditionally unstable and as cyclonic vorticity is always present in the lower levels before monsoon depression formation and as satellite pictures and earlier studies indicate considerable clouding and rainfall prior to the depression formation, cumulus heating should play an important role and conditions are favourable for the CISK mechanism to operate.

Also, before and during breaks the low level cyclonic vorticity over north Bay of Bengal is replaced by anti-cyclonic vorticity. This will inhibit cumulus convection and preclude growth of disturbances by CISK mechanism. Further, during and prior to breaks the vertical shear of the zonal wind is also more than normal over north Bay of Bengal. This also possibly inhibits convection. 


\section{Stability of the internal jet}

We can now examine the stability characteristics of the monsoon zonal flow. Charney and Stern (1962) showed that if the gradient of potential vorticity vanishes somewhere in the region, there is a possibility of combined barotropic-baroclinic instability of the internal jet.

Figure 7 shows the cross section of $U$ in July along $80^{\circ} \mathrm{E}$. Based on this and the $\sigma$ profile around $15-20^{\circ} \mathrm{N}$ (figure 8 ) we have computed the meridional gradient of potential vorticity as:

$$
\frac{\partial \bar{P}}{\partial y}=\beta-\frac{U_{J+1}+U_{J-1}-2 U_{J}}{\left(\triangle y^{2}\right)}+S_{k-1}\left(U_{k}-U_{k-2}\right)+S_{k+1}\left(U_{k}-U_{k+2}\right)
$$

where $S_{k}=\frac{f_{0}^{2}}{(\triangle p)^{2} \sigma_{k}}$

and presented in figure 9 .

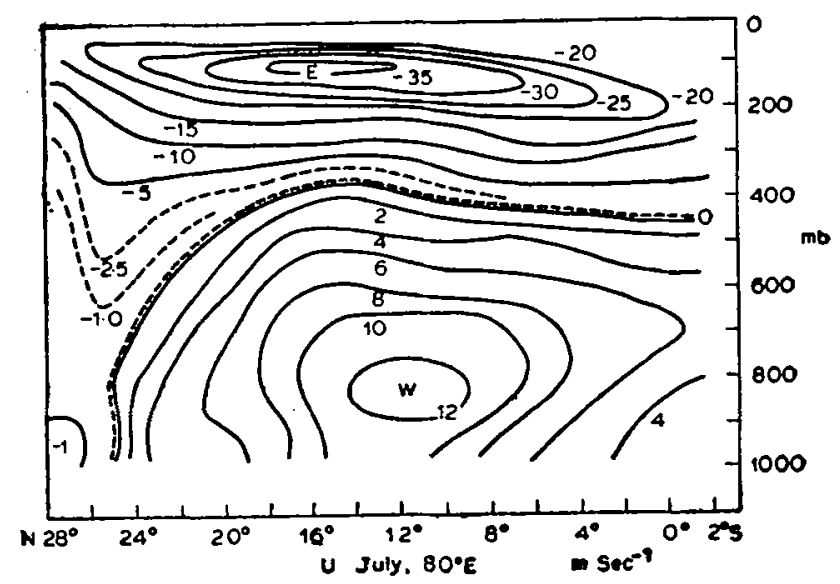

Figure 7. Cross-section of zonal wind along $80^{\circ} \mathrm{E}$ July.

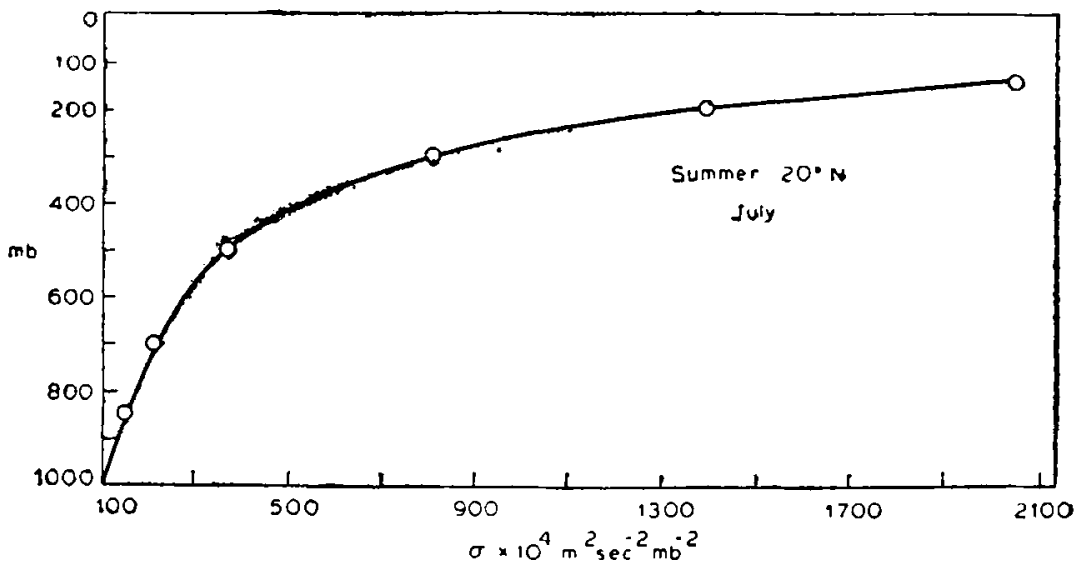

Figure 8. Static stability $\sigma \times 10 \mathrm{~m}^{2} \mathrm{sec}^{-2} \mathrm{mb}^{-2} \mathrm{July}, 20^{\circ} \mathrm{N}$. 


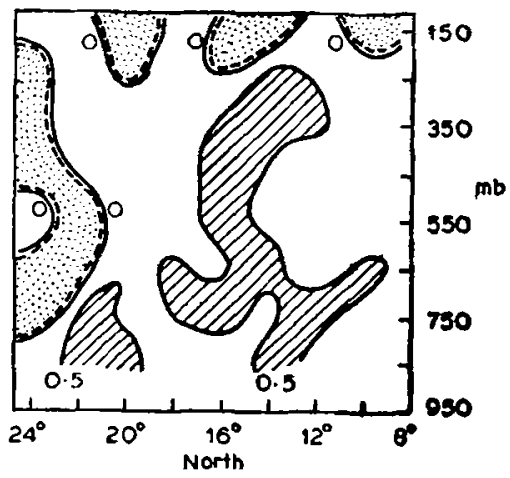

Figure 9. Meridional gradient of mean potential vorticity July; $80^{\circ} \mathrm{E}$.

This shows that the gradient of potential vorticity vanishes not only at 150 and 250 $\mathrm{mb}$ as shown by Shukla but also at almost all levels from 750 to $250 \mathrm{mb}$ around latitude 22 to $24^{\circ} \mathrm{N}$ i.e. in the region of the monsoon trough. The former i.e. the vanishing of $\partial \bar{P} / \partial y$ in the upper troposphere may yield disturbances in the upper troposphere as suggested by Keshavamurty (1971) and Shukla (1976). But the latter occurring at several mid-tropospheric levels in the region of the monsoon trough and contributed to mainly by the barotropic term i.e. $-\partial^{2} U / \partial y^{2}$ is likely to play an important role in the growth of monsoon disturbances. This feature is essentially due to the presence of the monsoon trough in the lower and middle tropospheres.

An examination of the meridional gradient of potential vorticity at $18^{\circ} \mathrm{N}$ without considering the horizontal shear of the basic current i.e.

$$
\frac{\partial \bar{P}}{\partial y}=\beta+S_{k-1}\left(U_{k}-U_{k-2}\right)+S_{k+1}\left(U_{k}-U_{k+2}\right)
$$

reveals that this vanishes around 200 and $100 \mathrm{mb}$ in the 10 and 20 level models indicating the possibility of instability of the upper tropospheric easterly jet only by the baroclinic term even in the absence of horizontal shear.

\section{Stability analysis of monsoon zonal flow with vertical shear}

It was seen in the earlier section that the necessary condition for the occurrence of combined barotropic-baroclinic instability is satisfied by the monsoon zonal flow. Even if this were not satisfied, the monsoon zonal flow could still be baroclinically unstable due to the potential temperature gradient at the bottom boundary. For example the midlatitude westerly current shows baroclinically unstable modes even with a two level model.

The structure of the observed disturbances suggests that they may not grow by drawing on zonal available potential energy. However in order to be very sure we now examine the stability characteristics of the monsoon zonal flow with only vertical shear, using a multi-level quasi-geostrophic model and eigen-value technique.

The perturbation potential vorticity equation at level $k$ is:

$$
\left(\frac{\partial}{\partial t}+U_{k} \frac{\partial}{\partial x}\right)\left(\frac{1}{f_{0}} \nabla^{2} \varphi_{k}^{\prime}+\frac{S_{k-1}}{f_{0}}\left(\varphi_{k}^{\prime}-\varphi_{k-2}^{\prime}\right)+\frac{S_{k+1}}{f_{0}}\left(\varphi_{k}^{\prime}-\varphi_{k+2}^{\prime}\right)\right)
$$




$$
+\frac{1}{f_{0}} \frac{\partial \varphi_{k}^{\prime}}{\partial x}\left(\beta+S_{k-1}\left(U_{k-2}-U_{k}\right)+S_{k+1}\left(U_{k+2}-U_{k}\right)\right)=0
$$

At level ' $l$ ' it is

$$
\begin{gathered}
\left(\frac{\partial}{\partial t}+U_{1} \frac{\partial}{\partial x}\right)\left(\frac{1}{f_{0}} \nabla^{2} \varphi_{1}^{\prime}-\frac{1}{f_{0}}\left(S_{2}\left(\varphi_{3}^{\prime}-\varphi_{1}^{\prime}\right)\right)\right) \\
+\frac{1}{f_{0}} \frac{\partial \varphi_{1}^{\prime}}{\partial x}\left(\beta-S_{2}\left(U_{1}-U_{3}\right)\right)=0 .
\end{gathered}
$$

At level ' $n$ ' it is

$$
\begin{aligned}
\left(\frac{\partial}{\partial t}+\right. & \left.U_{n} \frac{\partial}{\partial x}\right)\left(\frac{1}{f_{0}} \nabla^{2} \varphi_{n}^{\prime}+\frac{1}{f_{0}}\left(S_{n-1}\left(\varphi_{n-2}^{\prime}-\varphi_{n}^{\prime}\right)\right)\right) \\
& +\frac{1}{f_{0}} \frac{\partial \varphi_{n}^{\prime}}{\partial x}\left(\beta-S_{n-1}\left(U_{n-2}-U_{n}\right)\right)=0 .
\end{aligned}
$$

Assuming wave solutions of the type $\varphi_{k}^{\prime} \sim \exp [i k(x-c t)]$ and substituting in the potential vorticity equations, we obtain at level ' $k$ '

$$
\begin{aligned}
& \left(U_{k}-c\right)\left[-k^{2} \varphi_{k}^{\prime}+S_{k-1}\left(\varphi_{k-2}^{\prime}-\varphi_{k}^{\prime}\right)-S_{k+1}\left(\varphi_{k}^{\prime}-\varphi_{k+2}^{\prime}\right)\right] \\
& +\varphi_{k}^{\prime}\left[\beta+S_{k-1}\left(-U_{k-2}+U_{k}\right)+S_{k+1}\left(U_{k}-U_{k+2}\right)\right]=0
\end{aligned}
$$

i.e.

$$
\begin{aligned}
& \varphi_{k-2}^{\prime}\left[\left(U_{k}-c\right) S_{k-1}\right]+\varphi_{k}^{\prime}\left[\left(U_{k}-c\right)\left(-k^{2}-S_{k-1}-S_{k+1}\right)+\beta\right. \\
& \left.\quad-S_{k-1}\left(U_{k-2}-U_{k}\right)+S_{k+1}\left(U_{k}-U_{k+2}\right)\right]+\varphi_{k+2}^{\prime}\left[\left(U_{k}-c\right) S_{k+1}\right]=0
\end{aligned}
$$

There are $n$ such equation in the $n$ unknown $\varphi_{k}^{\prime}$. For nontrival solution, the determinant of the matrix of the coefficients must vanish

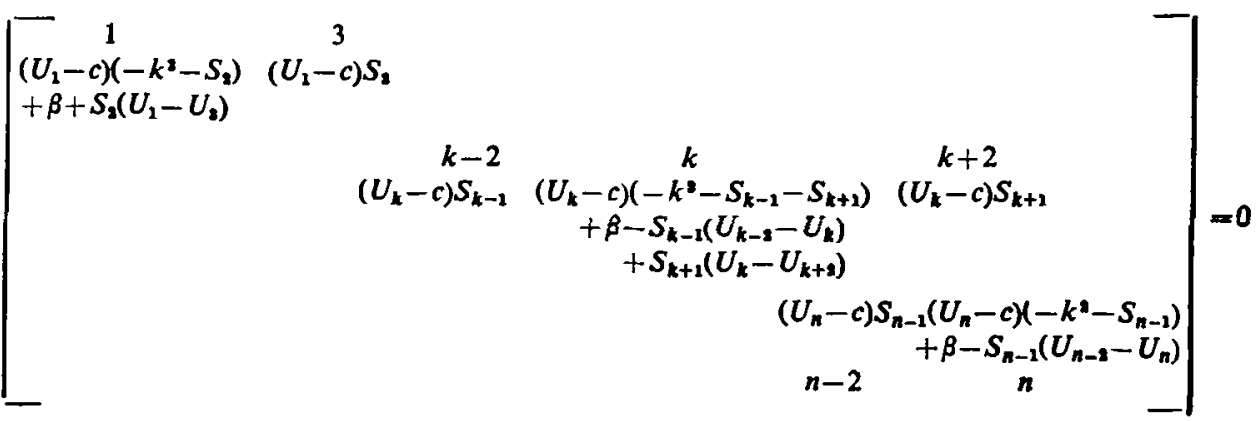


In matrix notation

$$
\text { or } \begin{aligned}
& (P-c Q)(R)=0 \\
& \left(P Q^{-1}-c I\right)(Q R)=0
\end{aligned}
$$

The problem reduces to finding the eigen values of $P Q^{-1}$ as shown by Haltiner (1963). We find the eigen values of the matrix $\left(P Q^{-1}\right)$ numerically and also the eigenvectors $Q R$ and thence $R$.

We experimented with monsoon zonal wind $(U)$ (figure 10$)$ and $\sigma$ profile at $18^{\circ} \mathrm{N}$ (Visakhapatnam) with a 10 level model. In the lower levels the profile was modified such that it has the same speed as the maximum speed above the friction layer. In other words the reduction of speed due to friction is not considered. The boundary condition used is $\omega=0$ at the top and at $1000 \mathrm{mb}$. The results indicate that there are some unstable modes which have reasonable growth rate (doubling time) but

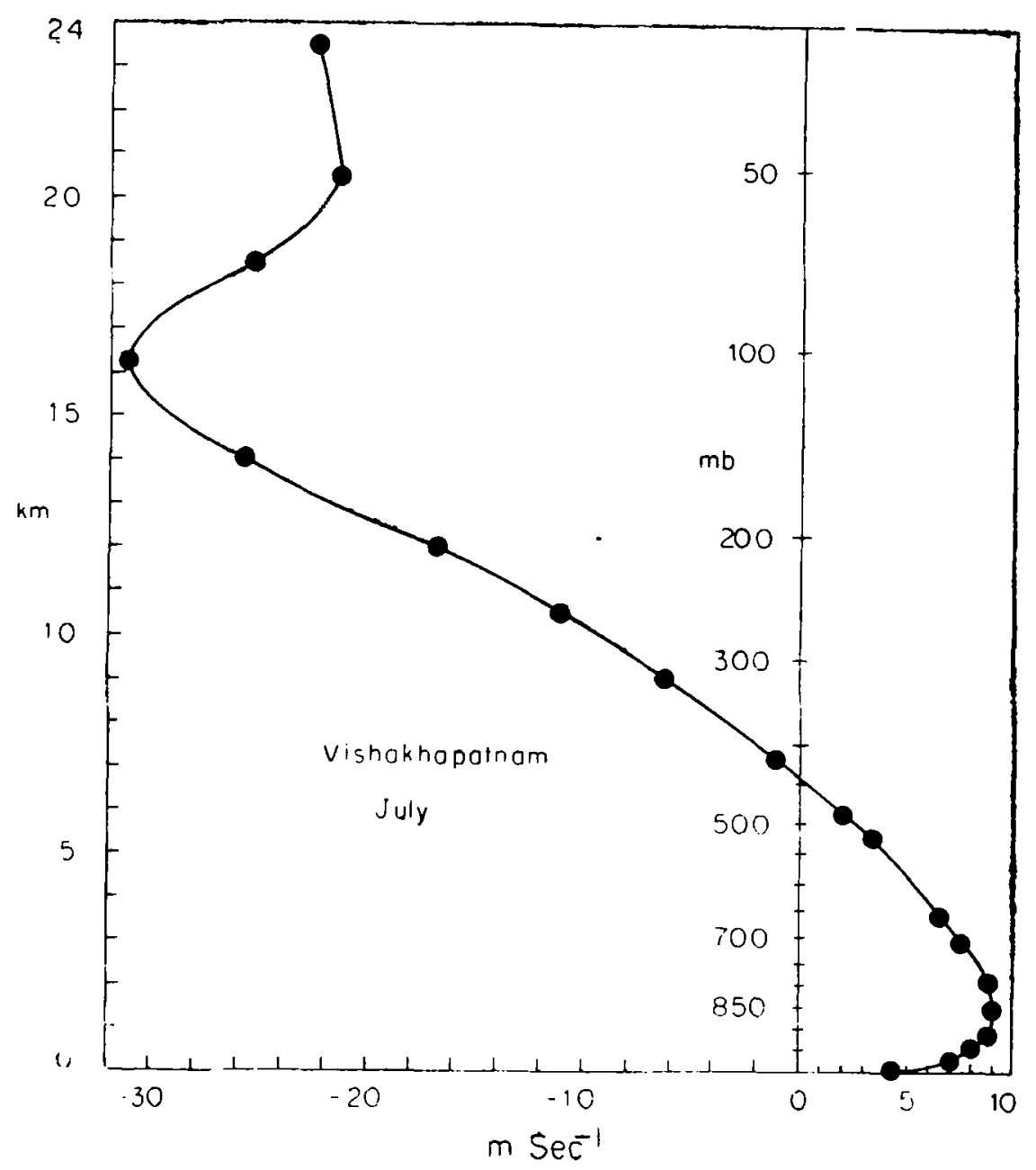

Figure 10. Mean U component, July, Visakhapatnam. 
whose structure does not conform to that of known disturbances. We have later experimented with a 20 level model and the spurious unstable modes disappear. Yanai and Nitta (1968) had similar experience with numerical work in connection with the barotropic instability problem. Even a zonal wind profile with speed increased to 1.5 times the normal speed at all levels does not yieid any unstable modes in the 20 level model during monsoon season.

\section{Barotropic instability of monsoon zonal current}

We have seen in section 3 that the potential vorticity of mean monsoon zonal flow has extreme values in the region of monsoon trough at all midtropospheric levels and this is mainly contributed by the barotropic term. Also the structure of the observed disturbances indicates that it may derive energy from zonal kinetic energy. We shall therefore examine whether the monsoon zonal current in the lower and middle tropospheres is barotropically unstable.

Starting from the perturbation vorticity equation:

$$
\left(\frac{\partial}{\partial t}+U \frac{\partial}{\partial x}\right) \nabla^{2} \psi^{\prime}+\left(\beta-\frac{\partial^{2} U}{\partial y^{2}}\right) \frac{\partial \psi^{\prime}}{\partial x}=0
$$

and introducing wave solution of the type

$$
\psi^{\prime}=\psi(y) \exp [i k(x-c t)]
$$

we get

$$
\begin{aligned}
& (U-c)\left(-k^{2} \psi+\frac{\partial^{2} \psi}{\partial y^{2}}\right)+\left(\beta-\frac{\partial^{2} U}{\partial y^{2}}\right) \psi=0 \\
& \stackrel{\psi=0}{-} n\left(U_{n}-c\right)\left(\frac{\psi_{n-1}-2 \psi_{n}}{\Delta y^{2}}-k^{2} \psi_{n}\right) \\
& +\left(\beta-\frac{U_{n+1}+U_{n-1}-2 U_{n}}{\Delta y^{2}}\right) \psi_{n}=0 \\
& \begin{array}{l}
\text { k }+1 \\
\text { k }\left(U_{k}-c\right)\left(\frac{\psi_{k+1}+\psi_{k-1}-2 \psi_{k}}{\Delta y^{2}}-k^{2} \psi_{k}\right)
\end{array} \\
& +\left(\beta-\frac{U_{k+1}+U_{k-1}-2 U_{k}}{\Delta y^{2}}\right) \psi_{k}=0 \\
& k-1
\end{aligned}
$$




$$
\begin{aligned}
& -1\left(U_{1}-c\right)\left(\frac{\psi_{2}-2 \psi_{1}}{\Delta y^{2}}-k^{2} \psi_{1}\right) \\
& +\left(\beta-\frac{U_{2}+U_{0}-2 U_{1}}{\Delta y^{2}}\right) \psi_{1}=0 \\
& \frac{\psi}{\psi=0} 0
\end{aligned}
$$

There are $n$ such equation in the $n$ unknowns $\psi_{k}$ and for non-trival solution the determinent of the matrix of coefficients must vanish. In matrix notation where $(P-c Q)(R)=0$

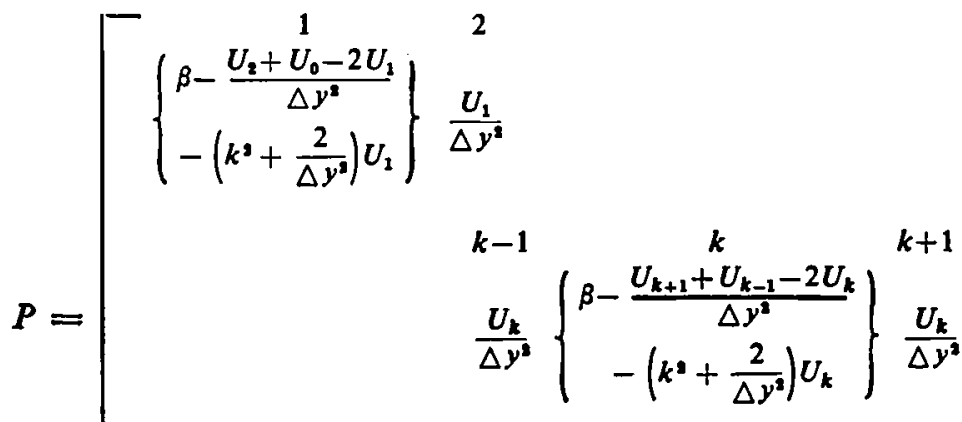

$$
\begin{aligned}
& \begin{array}{cc}
\frac{U_{n}}{\Delta y^{2}} & \beta-\frac{U_{n+1}+U_{n-1}-2 U_{n}}{\Delta y^{2}} \\
n-1 & -\left(k^{1}+\frac{2}{\Delta y^{2}}\right) U_{n}
\end{array} \\
& Q=\left[\begin{array}{ccccc}
1 & 2 & & \\
-\left(k^{2}+\frac{2}{\Delta y^{2}}\right) & \frac{1}{\Delta y^{2}} & & & \\
& & k-1 & k & k+1 \\
& & \frac{1}{\Delta y^{2}}\left(-k^{2}+\frac{2}{\Delta y^{2}}\right) & \frac{1}{\Delta y^{2}}
\end{array}\right. \\
& \underset{n-1}{\frac{1}{\Delta y^{2}}}\left(-k^{2}+\frac{2}{\Delta y^{2}}\right)
\end{aligned}
$$

and $R=\left(\begin{array}{c}\psi_{1} \\ \vdots \\ \psi_{k} \\ \vdots \\ \psi_{n}\end{array}\right)$

Now $\left(P Q^{-1}-c D\right)(Q R)=0$

The problem is now to find the eigen values of the matrix $P Q^{-1}$ and the eigen-vectors $Q R$ and thence $R$. 


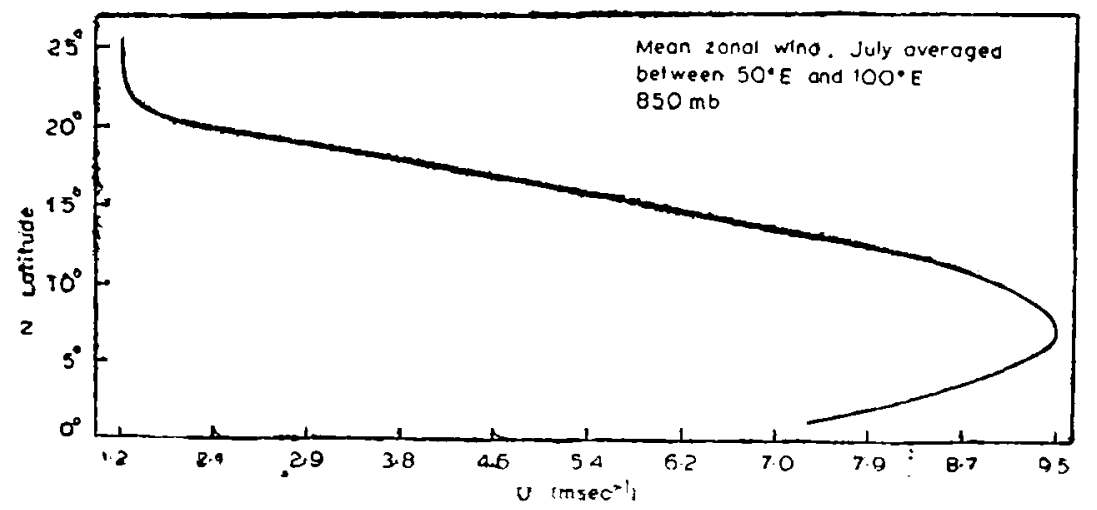

Figure 11. Profile of mean zonal wind, July, $850 \mathrm{mb}$; Average between $50^{\circ} \mathrm{E}$ and $100^{\circ} \mathrm{E}$.

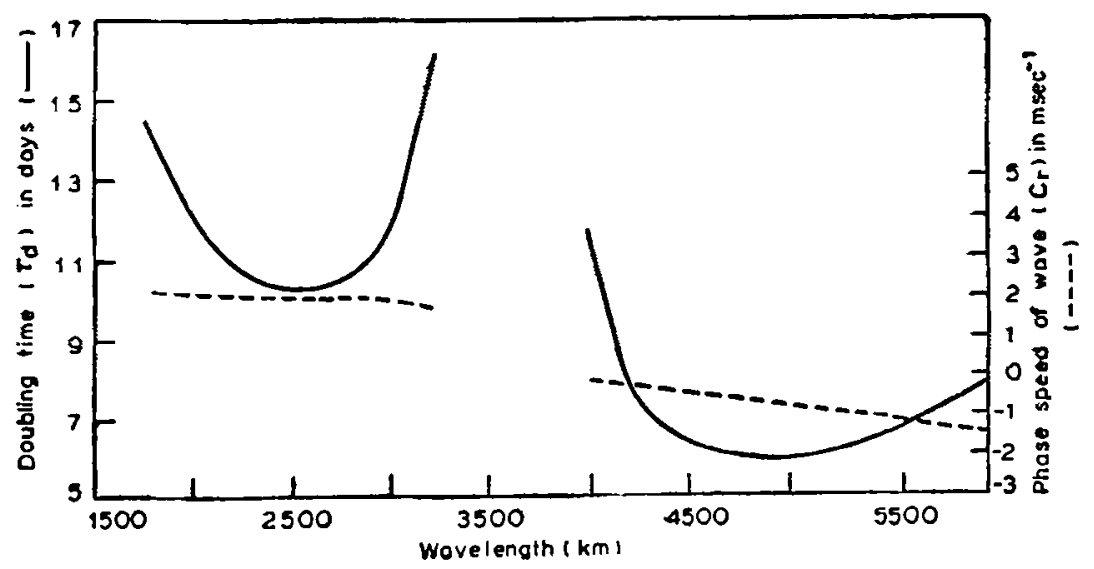

Figure 12. Scale dependence of barotropically unstable modes July, 850 mbs.

We have done such stability analysis for the profiles zonal mean wind for July averaged between longitudes $50^{\circ} \mathrm{E}$ and $100^{\circ} \mathrm{E}$ at the levels 850 (figure 11 ), 700 and $500 \mathrm{mb}$. The channel is from equator to $25^{\circ} \mathrm{N}$ and a $1^{\circ}$ grid is used. It is found that the zonal current at $850 \mathrm{mb}$ yields two very slowly growing unstable modes (figure 12) (i) with a scale of $2500 \mathrm{~km}$ and a slow doubling time of 10 days and a slow eastward speed of 2 mps. (ii) with a scale of around $5000 \mathrm{~km}$ and a doubling time of 6 days and a very slow westward speed of $1 \mathrm{mps}$.

These modes will perhaps grow much faster during strong monsoon epochs when horizontal shears are enhanced. The eastward speed of the first mode is not realistic. The westward movement of the observed disturbance is mainly due to the divergence term (Rao and Rajamani 1970).

\section{Conclusions}

The composite monsoon depression has a longitudinal scale of about $25^{\circ}$ longitude. It extends up to $300 \mathrm{mb}$ with maximum intensity around $700 \mathrm{mb}$. There is some 
westward movement of a cyclonic perturbation from Southeast Asia, but this may be a special feature of the data sample.

The disturbance has north-north-east - south-south-west tilt in the lower levels and thus can derive energy from zonal kinetic energy. Linear stability analysis yields very slowly growing unstable modes at $850 \mathrm{mb}$.

In the initial stages the monsoon depression has lower temperatures to the west and a consequent westward tilt with height indicating that eddy available potential energy of the disturbances cannot be increased by conversion from zonal available potential energy by large scale advection. A linear baroclinic stability analysis of the monsoon zonal flow indicates that the monsoon zonal current is not baroclinically unstable.

The profiles of potential vorticity of mean monsoon current indicate extreme values (i) in the upper troposphere and (ii) at several midtropospheric levels in the region of the monsoon trough indicating the possibility of combined barotropicbaroclinic instability.

The initial monsoon disturbances show a warm core in the upper levels. As the monsoon atmosphere is conditionally unstable and as there is generally cyclonic vorticity of the monsoon trough present in the lower levels, CISK is likely to be important for the development of monsoon disturbances as suggested by Keshavamurty (1971), Krishnamurti et al (1975) and Shukla (1976).

The monsoon depression initially develops possibly by the barotropic instability of the zonal current in the lower troposphere. Further development has to depend upon cumulus heating and CISK mechanism. Baroclinic instability is not important for the initial growth of monsoon disturbances.

\section{Acknowledgement}

The authors wish to thank the Director-General of Observatories for the facilities for conducting this research work.

\section{References}

Charney J G and Stern M C 1962 J. Atmos. Sci. 19159

Haltiner C J 1963 Tellus 15230

Keshavamurty R N 1971 On the Maintenance of the mean Indian Southwest Monsoon Circulation and the Structure and Energetics of the Monsoon Disturbances, Ph.D. Thesis, Mysore University

Koteswaram P and George C A 1958 Indian J. Meteorol. Geophys. 99

Krishnamurti T N et al 1975 J. Meteorol. Soc. Jpn. Ser. II 534

Man-kin Mak 1975 J. Atmos. Sci. 322246

Rao Y P 1976 Met. Monogr. No. 1/1976, India Meteorological Dept

Rao K V and Rajamani 1970 Indian J. Meteorol. Geophys. 21187

Shukla J 1976 Dynamics of Monsoon Distrurbances, Ph.D. Thesis, M.I.T.

Yanai M and Nitta T 1968 J. Meteorol. Soc. Jpn. 46389 